\title{
The Neighborhood Scale Variability of Airborne Particulates
}

\author{
William A. Harrison, David Lary, Brian Nathan, Alec G. Moore \\ William B. Hanson Center for Space Sciences, University of Texas at Dallas, Richardson, USA \\ Email: wah091020@utdallas.edu
}

Received 26 February 2015; accepted 8 May 2015; published 11 May 2015

Copyright (C) 2015 by authors and Scientific Research Publishing Inc.

This work is licensed under the Creative Commons Attribution International License (CC BY). http://creativecommons.org/licenses/by/4.0/

c) (i) Open Access

\begin{abstract}
Airborne particulates play a central role in both the earth's radiation balance and as a trigger for a wide range of health impacts. Air quality monitors are placed in networks across many cities globally. Typically these provide at best a few recording locations per city. However, large spatial variability occurs on the neighborhood scale. This study sets out to comprehensively characterize a full size distribution from 0.25 - $32 \mu \mathrm{m}$ of airborne particulates on a fine spatial scale (meters). The data are gathered on a near daily basis over the month of May, 2014 in a $100 \mathrm{~km}^{2}$ area encompassing parts of Richardson, and Garland, TX. Wind direction was determined to be the dominant factor in classifying the data. The highest mean $P_{2.5}$ concentration was $14.1 \pm 5.7 \mu \mathrm{g}^{-\mathrm{m}^{-3}}$ corresponding to periods when the wind was out of the south. The lowest $\mathbf{P M}_{2.5}$ concentrations were observed after several consecutive days of rainfall. The rainfall was found to not only "cleanse" the air, leaving a mean $\mathrm{PM}_{2.5}$ concentration as low as $3.0 \pm 0.5 \mu \mathrm{g} \cdot \mathrm{m}^{-3}$, but also leave the region with a more uniform $\mathbf{P M}_{2.5}$ concentration. Variograms were used to determine an appropriate spatial scale for future sensor placement to provide measurements on a neighborhood scale and found that the spatial scales varied, depending on the synoptic weather pattern, from $0.8 \mathrm{~km}$ to $5.2 \mathrm{~km}$, with a typical length scale of $1.6 \mathrm{~km}$.
\end{abstract}

\section{Keywords}

$\mathbf{P M}_{2.5}$, Variograms, Neighborhood Scale, Spatial Length

\section{Introduction}

Multiple studies have established a strong link between aerosols and health issues [1]-[4]. Several illnesses have been attributed to long-term exposure of aerosols [5]-[7]. However, even short term exposure can have an effect on cardiovascular/cardiopulmonary or respiratory health [1] [8]. Aerosols and particulates have even been 
shown to act as carriers for bacteria increasing risks for bacterial infections [9] [10]. According to a March 2014 World Health Organization (WHO) report, 7 million deaths in 2012 were attributable to air pollution [11]; a key part of this pollution is airborne particulates. Aerosols and particulates with a diameter of $2.5 \mu \mathrm{m}$ or smaller $\left(\mathrm{PM}_{2.5}\right)$ are a particular health risk due to their smaller size and ability to be breathed deeper into the lungs [8].

Traditionally air quality studies have used static sensors to gather measurements. This yields a single number representing the air quality of the entire region. Typically there is a lack of neighborhood-scale observations of airborne particulates, and many towns have no observations at all. To help address this issue, a machine learning approach was previously developed, by Lary et al. (2014) [12], to estimate daily global abundance of airborne particulates from multiple big, environmental, data sets.

Lary et al. (2014) [12] used ground-based observations along with satellite-based remote sensing (from NASA's seawifs and the two modis), meteorological data products (from the NASA merra), and machine learning to estimate global daily ground level $\mathrm{PM}_{2.5}$ concentrations from 1997-2014. The resolution of one pixel in this global estimate was $10 \mathrm{~km}$. However, for human health applications neighborhood-scale observations are preferable. One of the goals of this study was to look at the size distribution, in the size range 0.25 - $32 \mu \mathrm{m}$, and the spatial and temporal variability across a $10 \mathrm{~km}$ pixel of this global daily product.

This project used a mobile sensor package to gather data throughout the city mounted $1.5 \mathrm{~m}\left(5^{\prime}\right)$ above the ground. The mobile platform provided the ability to gather data on a neighborhood scale, allowing for a better understanding of the representativeness of this single $10 \mathrm{~km}$ pixel value for the actual air quality gradient within the region. This paper will start with a brief review of the sensor package, followed by a look at the flow regimes, and then examine the $\mathrm{PM}_{2.5}$ concentration variability and the aerosol size distribution. Finally, the question "What is the appropriate spatial resolution required to accurately characterize the $\mathrm{PM}_{2.5}$ abundance at a neighborhood scale?” will be explored.

\section{Instrumentation}

The instrumentation package included a Grimm NanoCheck 1365 particle spectrometer, a New Mountain Innovations NM150 Ultrasonic Weather Station, and an Arduino micro-controller. The NanoCheck 1365 particle spectrometer combines a Grimm 1109 aerosol-spectrometer with a Grimm 1320 nano-particle sensor allowing for a measurement range of 0.25 - $32 \mu \mathrm{m}$. The 1365 is a completely self-contained instrument utilizing a 14.4 V, 4.8 Ah Li Ion rechargeable battery pack for power and USB flash drive for data storage. Air is drawn into the instrument through the 1109 using an internal pump, with a flow rate of $1.2 \mathrm{l} \cdot \mathrm{min}^{-1}$, and then passed on to the 1320 through a pneumatic adapter block. The spectrometer was factory calibrated and was periodically sent back to the factory for recalibration. The 1109 has a $6 \mathrm{~s}$ sample-interval, while the 1320 runs a $10 \mathrm{~s}$ sample-interval.

The NM150 is a complete weather station with NIST calibrated sensors for measuring temperature, pressure and humidity as well as wind speed and direction using 4 ultra-sonic transducers. This sensor incorporates its own GPS receiver and compass allowing for true wind speed and direction calculations. The methods used in calculating temperature, pressure, humidity, and wind speed/direction are shown in Table 1 along with each sensor's range and accuracy.

Table 1. Methodology, range, and accuracy for the sensors used in this study. Data adapted from New Mountain Innovations [13] and Grimm Aerosol Technik [14].

\begin{tabular}{|c|c|c|c|}
\hline Variable & Method & Range & Accuracy \\
\hline Temperature & $\begin{array}{l}\text { Based on a negative temperature coefficient } \\
\text { thermistor that measures the ambient air temperature. }\end{array}$ & $\begin{array}{c}30^{\circ} \mathrm{C}-50^{\circ} \mathrm{C} \\
\left(22^{\circ} \mathrm{F}-122^{\circ} \mathrm{F}\right)\end{array}$ & $\begin{array}{l} \pm 15^{\circ} \mathrm{C}\left( \pm 2.7^{\circ} \mathrm{F}\right) @ 2 \text { knots } \\
\quad(2.3 \mathrm{mph}) \text { wind speed }\end{array}$ \\
\hline Pressure & $\begin{array}{l}\text { Measured using a temperature-compensated } \\
\text { silicon piezoresistive pressure sensor. }\end{array}$ & $\begin{array}{l}850-1150 \text { mbar } \\
(25-34 \text { in } \mathrm{Hg})\end{array}$ & $\pm 1.5 \%$ \\
\hline Humidity & Measured with a capacitive cell humidity sensor. & $10 \%-95 \% \mathrm{RH}$ & $\pm 4 \%$ \\
\hline Wind speed & Ultrasonic anemometer. & $\begin{array}{l}0.5 \text { - } 99.5 \text { knots } \\
(0.6-114.5 \mathrm{mph})\end{array}$ & $\begin{array}{l}\text { The greater of } \pm 1 \mathrm{knot} \\
\text { or } \pm 4 \%( \pm 1.1 \mathrm{mph})\end{array}$ \\
\hline Wind direction & Ultrasonic anemometer. & $0^{\circ}-360^{\circ}$ & $\pm 1.5^{\circ}$ \\
\hline Particle counts & Particle spectrometer (655 nm laser diode). & $0.25-32 \mu \mathrm{m}$ in 32 size bins & $\pm 3 \%$ \\
\hline
\end{tabular}


The NM150 is controlled using and reports data in standard NMEA 0183 formatted text strings. An Arduino ATmega 2560 micro-controller was used to read and write these text strings and the serial stream from the NanoCheck 1365. This micro-controller had $256 \mathrm{~KB}$ of flash memory, ran at $16 \mathrm{MHz}$, and was easily programmed using the Arduino programming language and development environment. Data received from the NM150 and the NanoCheck 1365 were stored on-board the arduino using an SD card reader and standard 2 GB SD card. Trey Kasling of Kasling Aircraft designed and 3D printed a window mount to attach the met sensor and particle spectrometer probe to the back window of a 2011 Volkswagen Jetta for the ground phase of the measurement campaign.

\section{Identifying Flow Regimes}

\subsection{Meteorological Context}

The meteorological context plays a pivotal role in the abundance of airborne particulates. The wind can carry particles from upwind sources, surface solar heating can dry out the ground and increase the availability of local dust sources, and humidity will determine the amount of moisture available that airborne particulates can absorb. Thus, the weather conditions throughout the region of interest during the data collections need to be examined.

Figure 1 panel a shows that the mean temperature across all days that data was collected was $25.0^{\circ} \mathrm{C} \pm 2.7^{\circ} \mathrm{C}$, with a range of $16.4^{\circ} \mathrm{C}$ to $29.4^{\circ} \mathrm{C}$. Panel b shows a mean pressure of $1015.4 \pm 4.0 \mathrm{mbar}$, with a range of 1007.4 mbar to 1025.1 mbar. Panel c shows a mean humidity of $45.6 \% \pm 8.1 \%$, with a range of $20.9 \%$ to $65.9 \%$. Panel d shows a mean wind speed of $3.6 \pm 1.3 \mathrm{~m} \cdot \mathrm{s}^{-1}$, with a range of $0.4 \mathrm{~m} \cdot \mathrm{s}^{-1}$ to $9.0 \mathrm{~m} \cdot \mathrm{s}^{-1}$, and panel e shows a mean wind direction of $151.5^{\circ} \pm 32.1^{\circ}$.

To objectively characterize the meteorological regimes a self organizing map (SOM) was used. The SOM classified the meteorological data into 10 different classes, each class corresponding to a distinct flow regime, in order to perform appropriate summary statistics for each flow regime (i.e. to compare like with like). SOMs are a way of reducing the dimensionality of multi-dimensional data sets [15]. They group like data sets together without any prior knowledge of the data to be classified, as well as determine the most dominant variable of the data set. The classes determined by the SOM show that wind direction is the dominant factor, as shown in Figure 1 (panel e). The classes overlap for all the other variables, while for wind direction the classes separate incrementally, with class 1 in the northerly direction and each class after progressing clockwise around the wind rose.
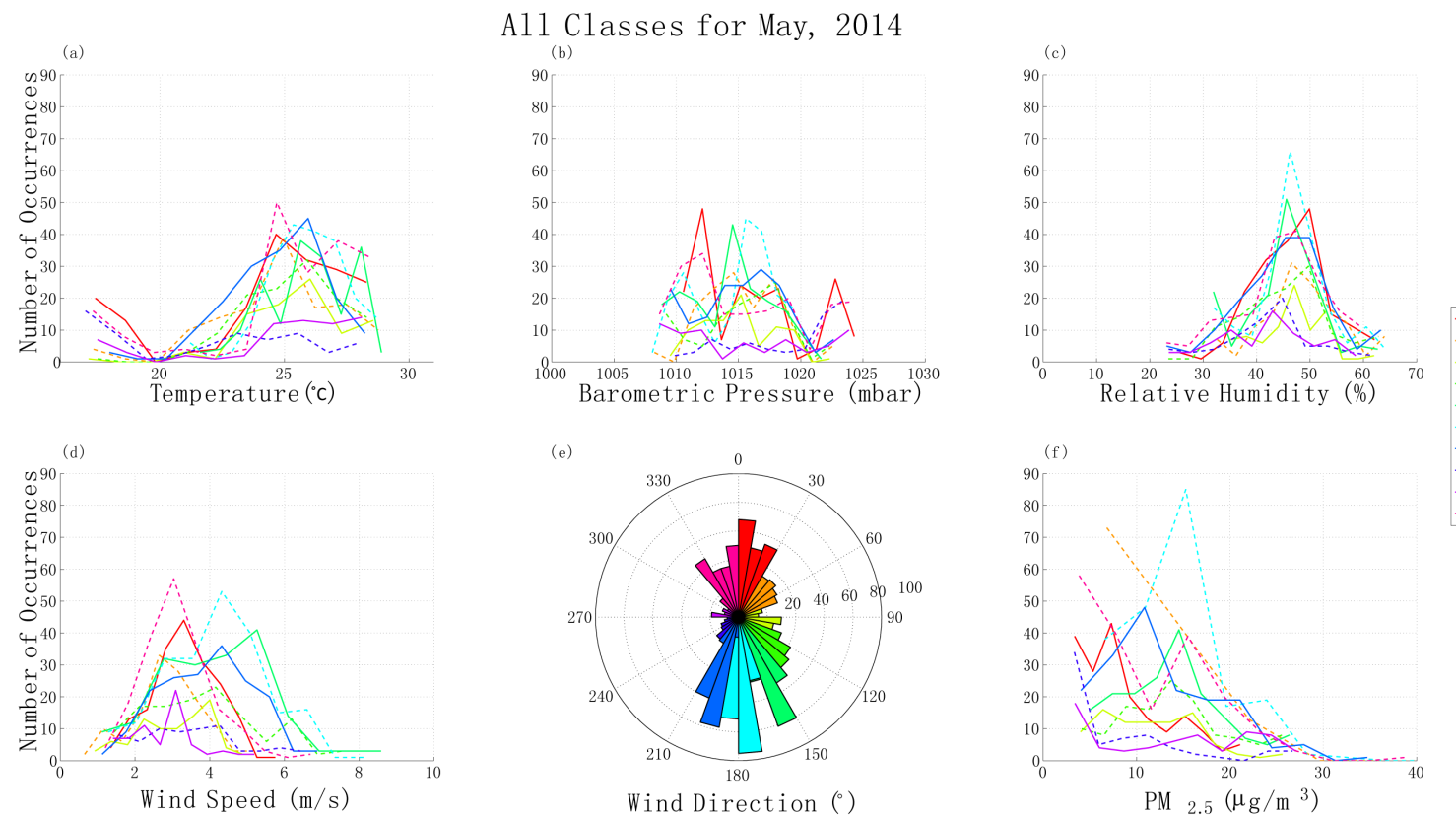

Figure 1. Frequency distributions for temperature (a); pressure (b); humidity (c); wind speed (d); wind direction (e); and $\mathrm{PM}_{2.5}$ concentration (f) for all classes of weather conditions experienced during our measurement campaign in Richardson and Garland, TX during May, 2014. Data was collected with a sample rate of $1 \mathrm{~Hz}$ during a 3 hour collection drive then averaged into 1 minute intervals. The different colors correspond to different classes assigned by the SOM. 
This is also illustrated when comparing the data gathered on May 23 and May 28 shown in Table 2. On May 23, the wind was mainly from the south, and on the $28^{\text {th }}$ the wind was mainly from the northeast. We see higher mean pressure, humidity, and $\mathrm{PM}_{2.5}$ concentration on May 23.

\section{2. $\mathrm{PM}_{2.5}$ Context}

Figure 2 shows the approximate $10 \mathrm{~km} \times 10 \mathrm{~km}$ area covered during daily measurement-gathering drives (outlined in red), representing 1 pixel of the global estimate from Lary et al. (2014) [12]. This drive area was chosen to include several different environments including residential areas, retail/commercial areas, and major highways: State Highway 75 is roughly down the center of the region of interest, President George Bush Tollway is across the northern border, and Interstate 635 is across the southern border. There are also industrial



Figure 2. Map depicting the area covered during driving campaigns with possible dust source locations. 1: Dorm and parking garage construction on the University of Texas at Dallas campus. 2: Large office building construction site. 3: Industrial area in Garland, TX including several large manufacturing, chemical, and food production facilities. Map produced using Google Earth. 
Table 2. Meteorological characterization of May 23, 2014 and May 28, 2014.

\begin{tabular}{ccc}
\hline Mean & May 23, 2014 & May 28, 2014 \\
\hline Primary wind direction $\left(^{\circ}\right)$ & $180-190$ & $30-40$ \\
Barometric pressure (mbar) & $1017.7 \pm 0.7$ & $1012.9 \pm 0.6$ \\
Relative humidity (\%) & $60.8 \pm 2.6$ & $52.6 \pm 2.5$ \\
$\mathrm{PM}_{2.5}\left(\mu \mathrm{g} \cdot \mathrm{m}^{-3}\right)$ & $19 \pm 2.8$ & $5.2 \pm 0.8$ \\
${\text { Temperature }\left({ }^{\circ} \mathrm{C}\right)}$ & $24.6 \pm 0.7$ & $25.1 \pm 0.6$ \\
Wind speed $(\mathrm{m} / \mathrm{s})$ & $3.4 \pm 1.1$ & $3.2 \pm 0.8$ \\
\hline
\end{tabular}

areas along the southern boarder and extending south of the region. There are four key types of sources affecting our region of interest: traffic, construction, industrial, and out of region (up-wind) sources.

The area marked " 1 " on the map is the University of Texas at Dallas campus. During the time of this campaign, construction of a new dormitory and parking garage was ongoing. The area marked " 2 " on the map depicts the construction site of a high-rise office building, and area " 3 " is the industrial sector in Garland, TX. This industrial sector contains several manufacturing, chemical, and food production facilities. All data was collected during daily 3-hour drives starting at area 1, driving to the northwest corner of the region of interest, and then crossing the region east to west/west to east, with a small detour in the northeast corner to gather highresolution data in a residential area, until reaching the southwest corner. The route then continued along State Highway 75 and over to the northeast corner. The region was then twice traversed north to south/south to north before returning to area "1". All collections where made between 11:00 and 14:00 Central Standard Time (CST).

The region of interest does not contain any air quality monitoring stations. However, the Texas Commission on Environmental Quality (TCEQ) does maintain a monitoring station approximately $3.5 \mathrm{~km}$ from the southwestern edge of the region. This station does not report $\mathrm{PM}_{2.5}$ data, but does report $\mathrm{PM}_{10}$ data as a $24 \mathrm{hr}$ average. For May, 2014 data for only four days are reported, two of them coinciding with data collections taken in this study. For May 17, 2014 TCEQ reported a 24 hour average $\mathrm{PM}_{10}$ concentration of $13 \mu \mathrm{g} \cdot \mathrm{m}^{-3}$. The mean $\mathrm{PM}_{10}$ concentration measured in the region of interest during this period was $13.2 \mu \mathrm{g} \cdot \mathrm{m}^{-3}$. For May 23, 2014 TCEQ reported a 24 hour average $\mathrm{PM}_{10}$ concentration of $21 \mu \mathrm{g} \cdot \mathrm{m}^{-3}$. The mean $\mathrm{PM}_{10}$ concentration measured in the region of interest during this period was $23.4 \mu \mathrm{g} \cdot \mathrm{m}^{-3}$.

To understand the spatial variability within the region of interest, knowledge is needed of how each of the four sources are distributed across the region. This knowledge can be acquired by using the SOM from the meteorological classification to understand how the meteorological data correlates to the $\mathrm{PM}_{2.5}$ concentration. There, the class with the highest $\mathrm{PM}_{2.5}$ concentration was class 6 characterized by a mean $\mathrm{PM}_{2.5}$ concentration of $14.1 \pm 5.7 \mu \mathrm{g} \cdot \mathrm{m}^{-3}$, with a range of $4.4 \mu \mathrm{g} \cdot \mathrm{m}^{-3}$ to $47.8 \mu \mathrm{g} \cdot \mathrm{m}^{-3}$. Class 6 also contained a mean temperature of $25.9^{\circ} \mathrm{C} \pm 1.6^{\circ} \mathrm{C}$, with a range of $20.8^{\circ} \mathrm{C}$ to $29.1^{\circ} \mathrm{C}$, a mean pressure of $1014.6 \pm 3.2 \mathrm{mbar}$, with a range of 1007.4 mbar to 1020.0 mbar, a mean humidity of $46.6 \pm 7.2 \%$, with a range of $30.2 \%$ to $65.9 \%$, a mean wind speed of $4.2 \pm 1.4 \mathrm{~m} \cdot \mathrm{s}^{-1}$, with a range of $0.9 \mathrm{~m} \cdot \mathrm{s}^{-1}$ to $8.5 \mathrm{~m} \cdot \mathrm{s}^{-1}$, and a mean wind direction of $176.5 \pm 20.3^{\circ}$, with a range of $188.0^{\circ}$ to $122.1^{\circ}$. The wind direction for this class is roughly out of the south, corresponding to area " 3 " on the map in Figure 2. As noted before, this area contains an industrial sector with several large manufacturing facilities, thus corresponding to industrial and other out of region sources. We will call this the southerly met class.

\subsection{Large Scale Transport}

The hysplit model was used to run forward and backward air parcel trajectories across the region. This model is only useful on scales much larger than the region of interest in this paper. It does, however, give insight to where the air that was sampled came from and how it traveled across the region. For May 23, 2014, the wind was out of the south blowing across the industrial sector just south of our region of interest and continuing on to the north. For May 28, 2014 the wind was coming out of the northeast (a more rural area of the region) and continued on to the southwest. Notice from Table 2 that the $\mathrm{PM}_{2.5}$ concentration for May 23 was much higher 
than on May 28, which is in agreement to the SOM showing the highest $\mathrm{PM}_{2.5}$ concentrations with wind out of the south.

\subsection{Epochs}

Figure 3 is an overview of the entire study aimed at putting the key features of the analysis together. The data collections were grouped into epochs, labeled A-G, based on size spectrum (a), $\mathrm{PM}_{2.5}$ concentration (b), and variogram range (d). Note that data was not gathered every day and was only available for the days marked on the horizontal axis. The characterization of each epoch is displayed in Table 3. Epochs D and F have the lowest mean $\mathrm{PM}_{2.5}$ concentration of $3.0 \pm 0.5 \mu \mathrm{g} \cdot \mathrm{m}^{-3}$ and $5.2 \pm 0.8 \mu \mathrm{g} \cdot \mathrm{m}^{-3}$ respectively. Both of these epochs occur right after consecutive days of rain.

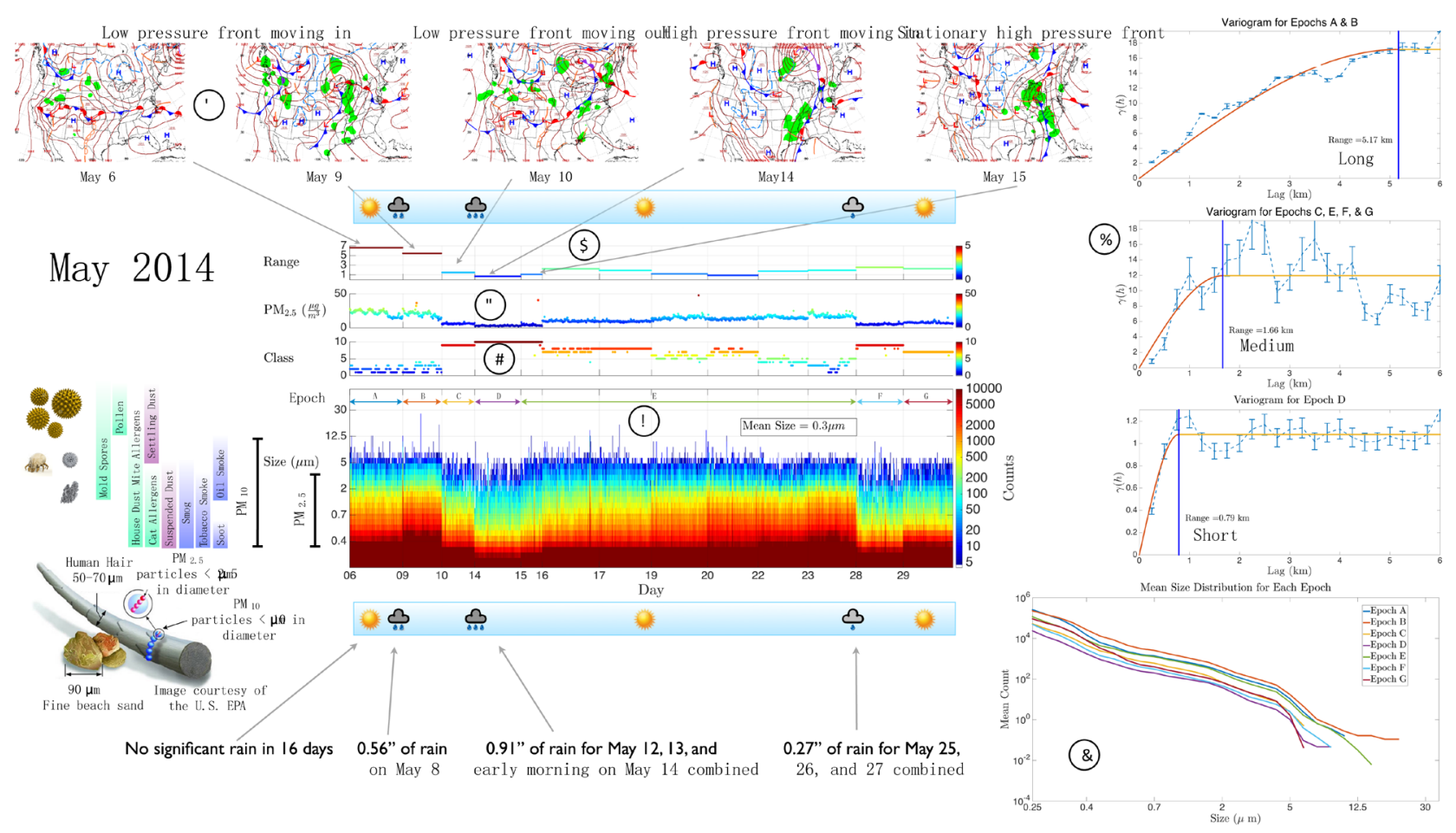

Figure 3. Overview of study with key features including size spectrum, $\mathrm{PM}_{2.5}$ concentration, and weather summary.

Table 3. Characterization of each epoch.

\begin{tabular}{|c|c|c|c|c|c|c|c|}
\hline Epoch & A & $\mathrm{B}$ & C & $\mathrm{D}$ & $\mathrm{E}$ & $\mathrm{F}$ & G \\
\hline Length scale (km) & 6.6 & 5.4 & 1.5 & 0.7 & 1.66 & 2.6 & 2.3 \\
\hline Time since rain (days) & 16 & 1 & 2 & $<1$ & $1+$ & 1 & 2 \\
\hline Mean wind direction $\left(^{\circ}\right)$ & $168.9 \pm 34.8$ & $217.7 \pm 34.6$ & $176.9 \pm 28.3$ & $326.1 \pm 44$ & $148.4 \pm 20.5$ & $47.9 \pm 30$ & $34 \pm 28$ \\
\hline $\mathrm{PM}_{2.5}\left(\mu \mathrm{g} \cdot \mathrm{m}^{-3}\right)$ & $20.5 \pm 4.2$ & $20.1 \pm 4.2$ & $6.1 \pm 0.7$ & $3.0 \pm 0.5$ & $13.7 \pm 3.7$ & $5.2 \pm 0.8$ & $7.6 \pm 1.2$ \\
\hline EPA class & Moderate & Moderate & Good & Good & Moderate & Good & Good \\
\hline Mean temp $\left({ }^{\circ} \mathrm{C}\right)$ & $25.6 \pm 1$ & $27.6 \pm 1$ & $26.3 \pm 0.9$ & $17.7 \pm 0.8$ & $24.3 \pm 1.6$ & $25.1 \pm 0.6$ & $27.6 \pm 0.7$ \\
\hline Mean pressure (mbar) & $1009.3 \pm 0.7$ & $1011.6 \pm 0.7$ & $1010.6 \pm 0.6$ & $1023.3 \pm 0.7$ & $1016.7 \pm 1.6$ & $1012.9 \pm 0.6$ & $1011.8 \pm 0.7$ \\
\hline Mean humidity (\%) & $34 \pm 2.5$ & $47.5 \pm 5$ & $47 \pm 2.5$ & $10.9 \pm 3.0$ & $47.9 \pm 7.4$ & $52.6 \pm 2.5$ & $48.8 \pm 2.3$ \\
\hline Mean wind speed $\left(\mathrm{m} \cdot \mathrm{s}^{-1}\right)$ & $3.6 \pm 1.6$ & $3.8 \pm 1.2$ & $3.9 \pm 1.3$ & $3.8 \pm 1.1$ & $3.7 \pm 0.5$ & $3.2 \pm 0.8$ & $3.0 \pm 0.8$ \\
\hline Mean size $(\mu \mathrm{m})$ & 0.29 & 0.31 & 0.3 & 0.3 & 0.3 & 0.29 & 0.29 \\
\hline
\end{tabular}


Unlike the previous SOM classification, each epoch was dominated, in part, by the local rainfall as denoted by the icons above and below the central plots. The majority of the epochs consist of single data collections, the sole exception is epoch E. This epoch contains seven data collections. It also represents the longest consecutive days without rainfall during the collection period.

Variograms were examined for each epoch to objectively characterize the length scale (range) of the $\mathrm{PM}_{2.5}$ spatial variability, shown in Figure 3(d). Variograms are functions that relate spatial separation and variance to provide an understanding of the length scales of spatial variability [16] [17] and have previously been shown useful in determining spatial resolutions for air quality measurements [18]. The algorithm developed by Wolfgang Schwanghart [19], implemented in MATLAB was used for this study. Here three general categories where found: long, medium, and short length scales (e). Epoch D had the shortest length scale at $0.8 \mathrm{~km}$.

\subsection{Variability}

Throughout the campaign, considerable variability was not only observed across the drive during any given day, but also from one day to another, particularly if it had just rained. Figure 4 shows the data captured on the last day of epoch E, May 23, 2014 (a), and epoch F, May 28, 2014 (b), respectively. No data was gathered between these two drives due to rain. On May 23, considerable variability in $\mathrm{PM}_{2.5}$ concentration is seen across the drive. Notice on May 28, after several days of rainfall, that the concentration and range dropped across the entire region, indicated by the change in the range of the colorscale.

The concentration decrease is better indicated by the histogram and frequency distributions of the $\mathrm{PM}_{2.5}$ concentrations shown in Figure 5. The color-scale used follows the aqi, defined by the EPA [20] and shown in Table 4. For May 23, Figure 5(a), a median concentration of $19 \mu \mathrm{g} \cdot \mathrm{m}^{3}$ is seen with the highest measured concentration of $34 \mu \mathrm{g} \cdot \mathrm{m}^{3}$. This puts the measurements into the moderate range on the aqi. While after several days of rain, on May 28 (b) a median is seen of only $5 \mu \mathrm{g} \cdot \mathrm{m}^{3}$, with a high measurement of $15.8 \mu \mathrm{g} \cdot \mathrm{m}^{3}$, which keeps the measurements in the good range on the aqi. Although both days have similar distributions, May 23 shows a much wider spread and longer tail than May 28, which has a standard deviation of $0.88 \mu \mathrm{g} \cdot \mathrm{m}^{3}$, less than half the $2.8 \mu \mathrm{g} \cdot \mathrm{m}^{3}$ deviation of May 23. Thus, the rainfall between the data collections not only "cleansed" the air, but left the region with a much more uniform concentration.

\subsection{Size Spectrum}

Figure 3(a) shows the size distribution by class for the month of May, 2014. The vertical axis shows particle size bins in microns and the horizontal axis shows the day of data collection. The colorscale represents the number of particles counted in the sample. It is clear that the smaller particles vastly outnumber the larger particles. The mean particle size for the entire data set was only $0.3 \mu \mathrm{m}$.

The data collections were grouped by epoch, and the mean count for each epoch was plotted against the size bin shown in Figure 3(f). This, essentially, is looking at a slice through the size distribution in (a). In both, higher particle counts are seen for epochs A and B, followed by a drop in epoch C and a larger drop in epoch D. This drop in aerosol concentration was due to the rainfall "washing" the atmosphere. Prior to data collection, the area did not see significant rainfall for 16 days, then had $14.2 \mathrm{~mm}(0.56$ ") of rain fall over the course of a few hours on the morning of May 8. The particle counts for epoch C and D, corresponding to this time period are the highest for the month. The region then received 4 days of sustained rainfall totaling $23.1 \mathrm{~mm}(0.91 ")$, from May

Table 4. AQI defined by the EPA. table adapted from [20].

\begin{tabular}{ccc}
\hline AQI catagory & Index values & $\mathrm{PM}_{2.5}$ breakpoints $\left(\mu \mathrm{g} \cdot \mathrm{m}^{-3}\right)$ \\
\hline Green good & $0-50$ & $0.0-12.0$ \\
Yellow moderate & $51-100$ & $12.1-35.4$ \\
Orange unhealthy for sensitive groups & $101-150$ & $35.5-55.4$ \\
Red unhealthy & $151-200$ & $55.5-150.4$ \\
Violet very unhealthy & $201-300$ & $250.5-350.4$ \\
Purple hazardous & $301+$ & $350.5+$ \\
\hline
\end{tabular}




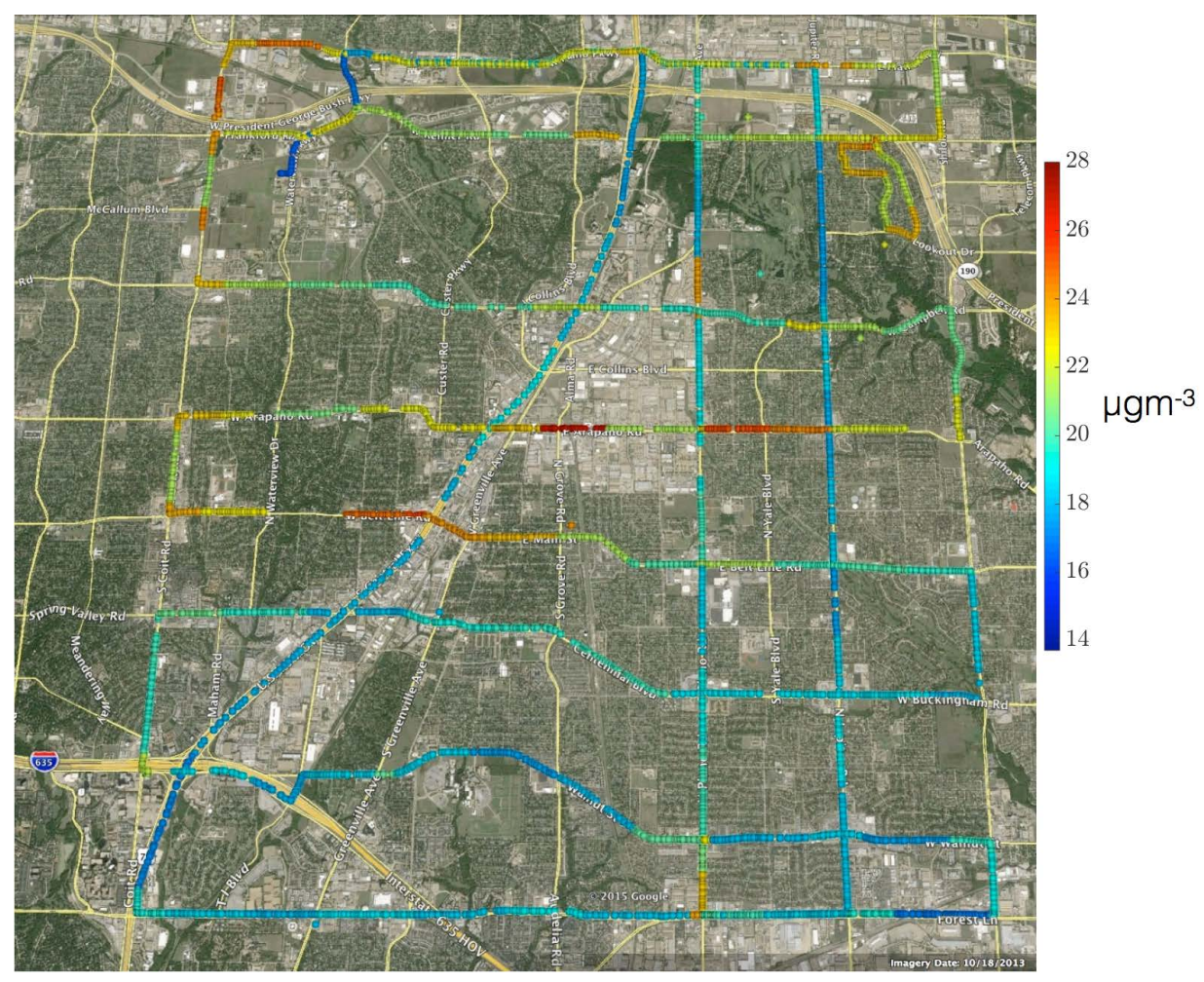

(a)

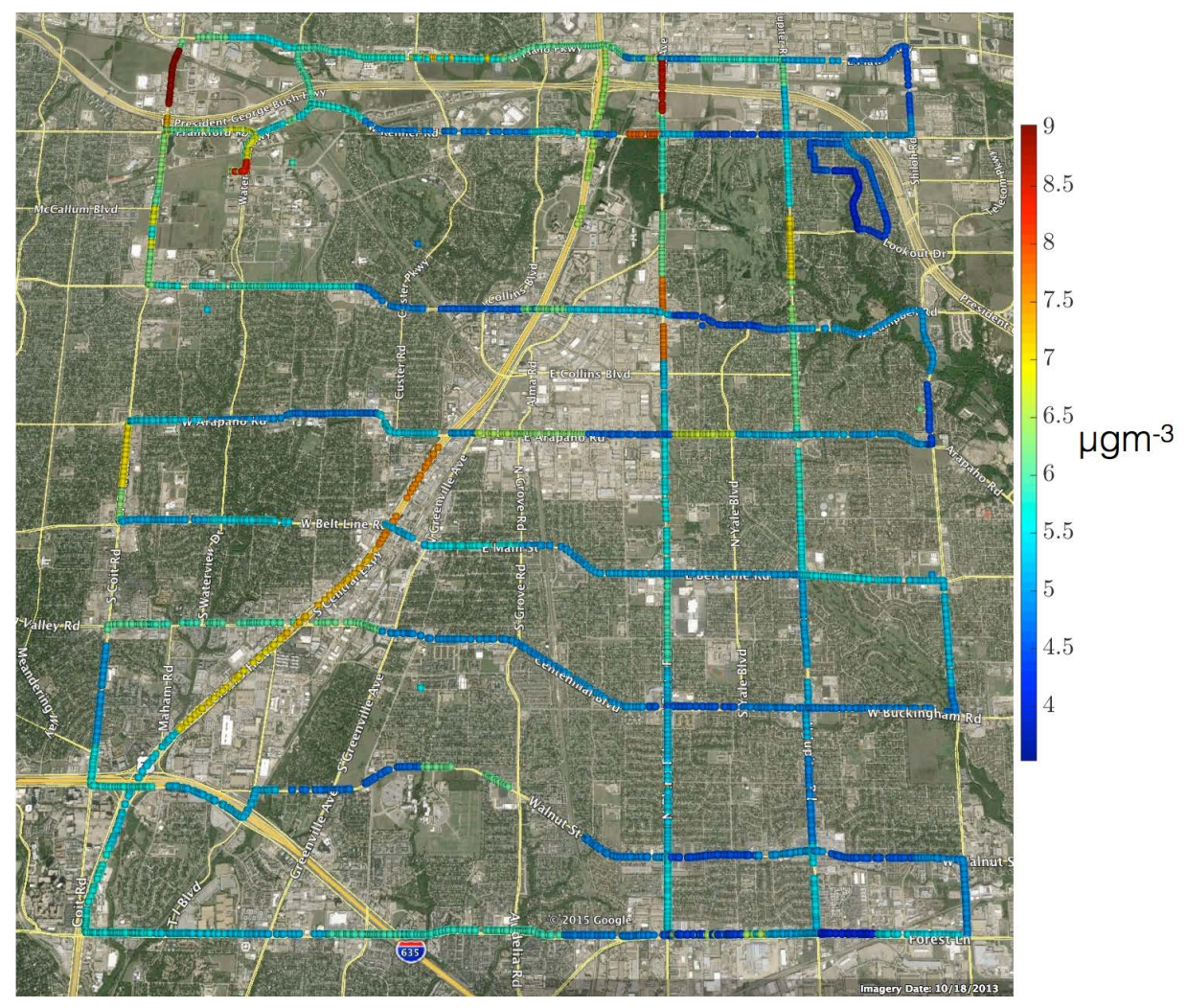

(b)

Figure 4. Data captured on May 23, 2014 (a) and May 28, 2014 (b). Color scale indicates PM$_{2.5}$ concentration. 
PM2. 5 Abundance for May 23, 2014
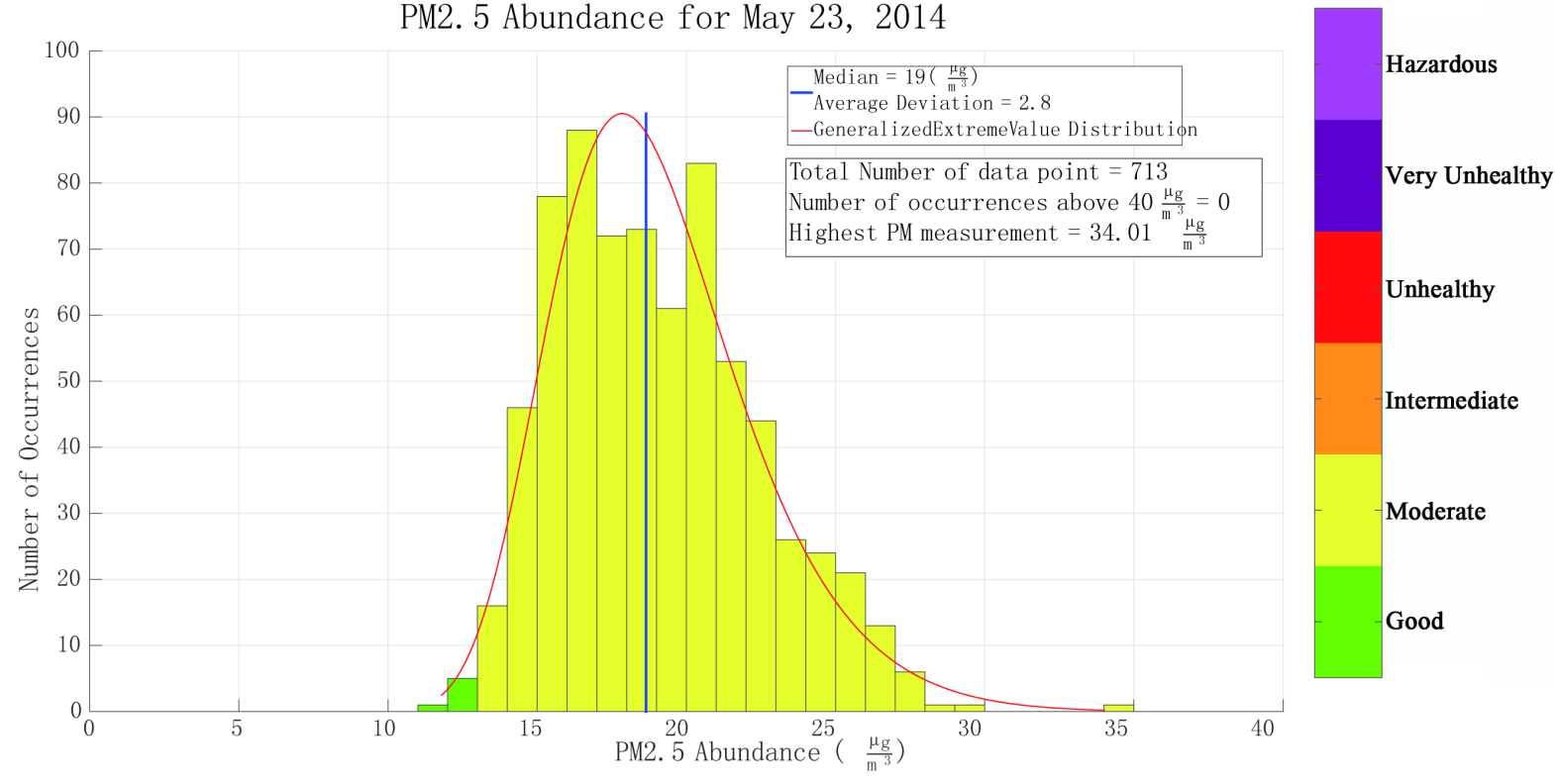

(a)

PM2. 5 Abundance for May 28, 2014
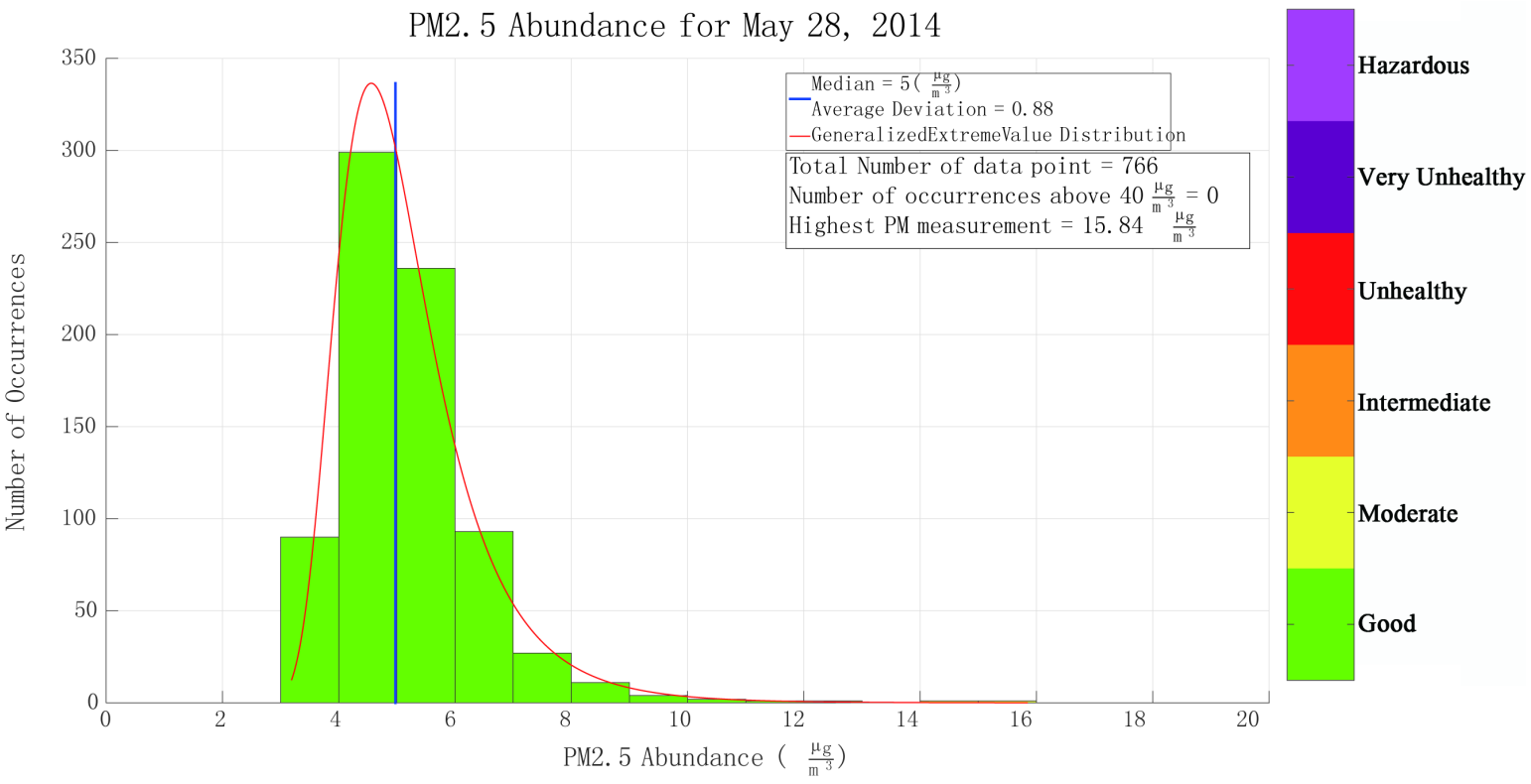

(b)

Figure 5. Histograms and frequency distributions for May 23, 2014 (a) and May 28, 2014 (b). The color of the histogram represents the aqi defined by the EPA.

12 through the morning of May 14. Epoch D, corresponding to the data collected on May 14, showed the lowest particle counts for the month. Epoch E corresponds to several days of no rain and shows a steady increase of particle counts ending with 3 days of slight rainfall totaling only $6.86 \mathrm{~mm}(0.27 ")$ on May 25 - 27. However even though the amount of rain was approximately half of what fell very quickly on May 8 , epoch $\mathrm{F}$ shows a decrease in particle counts. This indicates that a quick rainfall may not wash particles out of the atmosphere. An extended period of rain is needed.

To objectively characterize the different types of size distribution observed, an SOM was used to classify the particle counts into 10 classes using each size bin as a variable, as seen in Figure 3(c). For most epochs, the data falls into several classes, but epochs $C$ and $D$ fall solely into classes 9 and 10, respectively. Comparing the size 
distribution by class, the class with the highest $\mathrm{PM}_{2.5}$ concentration was class 1 , which falls mostly in epochs $\mathrm{A}$ and B (Figure 3(b)). This class had a mean southerly wind direction of $181.25^{\circ} \pm 37.76^{\circ}$, with a range of $215.82^{\circ}$ to $52.79^{\circ}$, a mean $\mathrm{PM}_{2.5}$ concentration of $20.86 \pm 4.27 \mu \mathrm{g} \cdot \mathrm{m}^{3}$, with a range of $13.13 \mu \mathrm{g} \cdot \mathrm{m}^{3}$ to 28.12 $\mu \mathrm{g} \cdot \mathrm{m}^{3}$, and a mean size of $0.298 \mu \mathrm{m}$. This is called the southerly size class. This is interesting, as wind direction was not a variable included when training the size distribution SOM, yet classifications corresponding to distinct wind direction are still seen. Furthermore, the class with the highest concentration corresponded to wind out of the south, although with a higher mean $\mathrm{PM}_{2.5}$ concentration than the southerly met class.

\subsection{Spatial Scale}

This study used an approach of recursive subdivision to examine the spatial scales of the data. First, the median value of the entire $10 \times 10 \mathrm{~km}$ measurement area was calculated. The area was then subdivided into a $2.5 \times 2.5$ $\mathrm{km}$ grid, then again down to a $1.25 \times 1.25 \mathrm{~km}$ grid, and the median value of each grid section was calculated. Figure 6 panel "a" shows the results from May 14, May 16, and May 6 respectively. These three days are examples of a short, medium, and long spatial scale. The color scales on these plots are not in the same range to help highlight the changes in median values for each data set represented. In the median concentration plots (Figure 6 panel "a"), for both the short and medium spatial scales, the $1.25 \mathrm{~km}$ grid shows much more detail than the $2.5 \mathrm{~km}$ grid. However, for the long spatial scale, the $1.25 \mathrm{~km}$ grid shows only marginal improvement in detail over the $2.5 \mathrm{~km}$ grid. For all three days, the sets indicate that a spatial scale smaller than $10 \mathrm{~km}$ is necessary for neighborhood scale measurements.

In order to determine the appropriate spatial scale for future measurements, variograms for each day were created. The length scale (range) for each day is presented in Figure 3(d). Epochs A and B have the longest ranges with epoch $\mathrm{C}$ having the shortest ranges. Unlike the pattern previously seen with particle counts and $\mathrm{PM}_{2.5}$ concentration; a steady increase in range throughout epoch $\mathrm{E}$ is not seen and an increase in range in epoch $\mathrm{F}$ is seen instead of the decrease observed in particle count and concentration. This is possible due to a dependency on the synoptic weather systems discussed further below.

The variograms were separated into 3 groups, based on range, and an average variogram for each group was

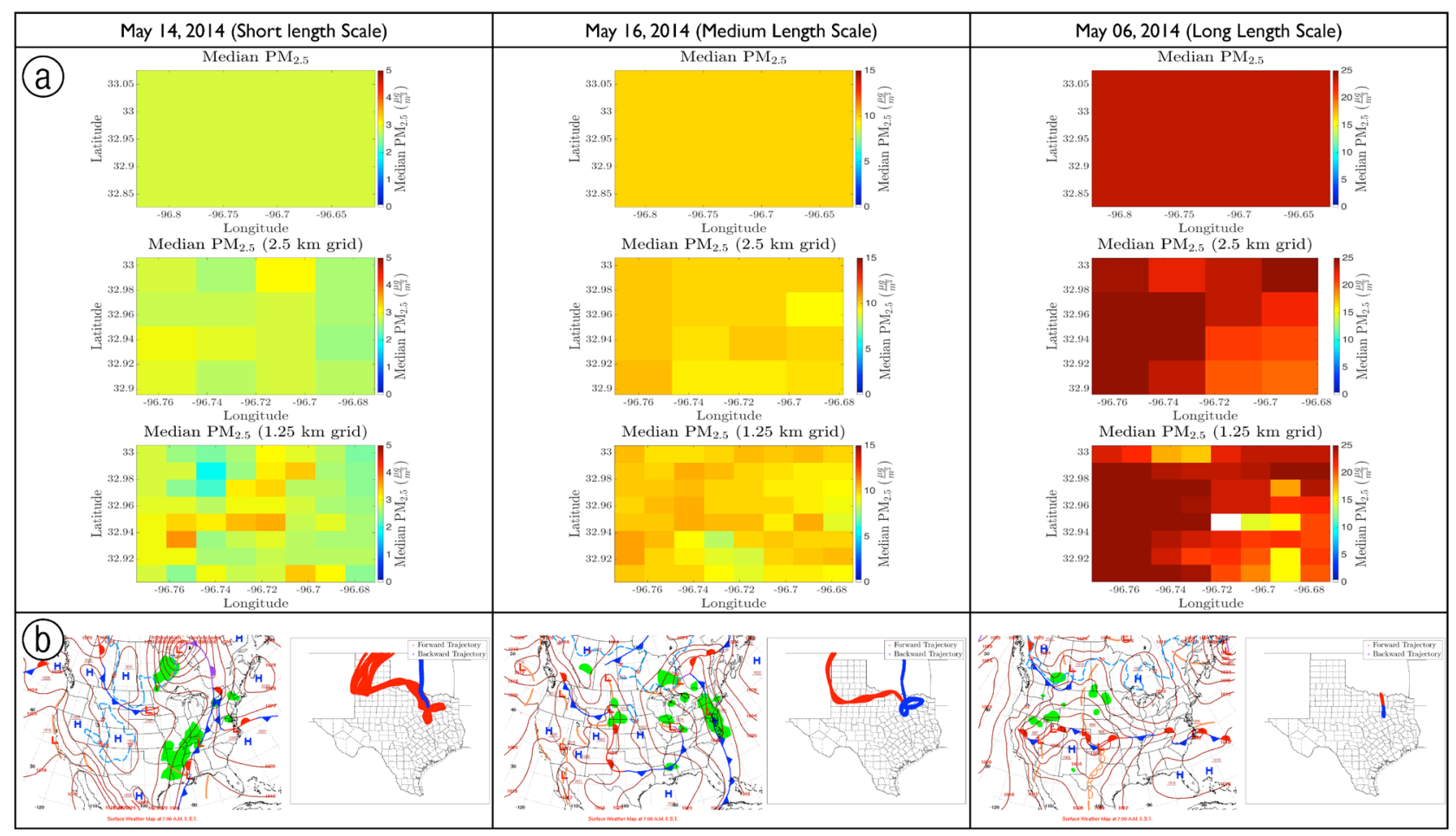

Figure 6. Spatial scale comparison between short variogram range $(0.8 \mathrm{~km})$, medium variogram range $(1.7 \mathrm{~km})$, and long variogram range $(5.2 \mathrm{~km})$. 
calculated. The first group, shown in Figure 3(e), represents the long spatial scale, with a mean range of $5.2 \mathrm{~km}$. The second group represents the medium spatial scale, with a mean range of $1.7 \mathrm{~km}$, and the third group represents the short spatial scale, with a mean range of $0.8 \mathrm{~km}$.

The short scale group consists solely of epoch D and may be considered an outlier. In this case, we might conclude that a long length scale is associated with high $\mathrm{PM}_{2.5}$ concentration. However, toward the end of epoch $\mathrm{E}, \mathrm{PM}_{2.5}$ concentration (Figure 3(a)) approaches that of epochs A and B, but has a much lower range (Figure $3(\mathrm{~d})$ ). Thus, length scale is not a simple function of $\mathrm{PM}_{2.5}$ concentration.

Since the long scale group only has two epochs as members then perhaps both the short and long scales can be considered outliers. In this case a simple conclusion can be made that the appropriate spatial scale for future measurements is approximately $1.7 \mathrm{~km}$. This may be good enough for the majority of studies.

Rain was a leading factor in affecting particle distributions. However, the overall pressure system had a greater affect on the spatial scales. Notice, in Figure 3(a), during epochs A and B the spatial scale (d) is approximately $5 \mathrm{~km}$. This is after a significant number of days without rain. However, at the end of epoch E, a similar number of days without rain, the spatial scale does not approach a similar range. Also, note that epoch F, occurring after several days of rain, similar to epoch D, does not have the drop in spatial scale seen in epoch D.

A possible cause for the change in spatial scale sensitivity can be seen in the synoptic weather systems shown in Figure 3(g). During epochs A and B, a low pressure system was moving into the region, and moved out during epoch C. A high pressure system moved in during epoch D and moved out of the region on May 19 - 20 (not shown), corresponding to the dip in range during epoch E. Another low pressure front began moving into the region on May 20, corresponding to the increase in range from that point on in epoch E. These weather systems are further illustrated in the wind patterns of the region.

Figure 6(b) shows a representative synoptic scale weather system map and forward/backward wind trajectories produced using the hysplit model for each of the 3 spatial scales: short, medium, and long. The red trace represents forward trajectories, and the blue trace represents backward trajectories. The short spatial scale corresponds to a high pressure system moving in from the southwest, with the wind trajectory showing wind diverted back into the region. In the medium spatial scale, a front had just passed through the region, but the pressure systems were stable, with the wind trajectories showing the wind coming from the east and moving off to the northwest. The long spatial scale corresponds to a low pressure front moving in from the north but still out of the region with winds moving in a straight south to north flow.

\section{Conclusions}

This study looked at the size distribution, in the size range 0.25 - $32 \mu \mathrm{m}$, and the spatial and temporal variability across a $100 \mathrm{~km}^{2}$ area encompassing parts of Richardson, and Garland, TX. This area represented 1 pixel of data in the satellite-based ground level $\mathrm{PM}_{2.5}$ concentration estimate of Lary et al. (2014) [12]. This project used a mobile sensor package to gather data throughout the city mounted $1.5 \mathrm{~m}$ above the ground. This mobile platform provides the ability to gather data on a neighborhood scale allowing us to better understand the representativeness of this single $100 \mathrm{~km}^{2}$ pixel value to the actual air quality gradient within the region.

To objectively characterize the meteorological regimes, an SOM was used to classify the meteorological data into 10 different classes. Wind direction was determined to be the dominant factor in classifying the data. A second SOM was used to classify the size distribution by size bin. Both SOM classifications determined that the highest $\mathrm{PM}_{2.5}$ concentrations corresponded to periods when the wind was out of the south, the southerly met class had a mean $\mathrm{PM}_{2.5}$ concentration of $14.1 \mu \mathrm{g} \cdot \mathrm{m}^{-3}$, and the southerly size class had a mean $\mathrm{PM}_{2.5}$ concentration of $20.86 \mu \mathrm{g} \cdot \mathrm{m}^{-3}$.

The lowest $\mathrm{PM}_{2.5}$ concentrations where observed after several consecutive days of rainfall where mean $\mathrm{PM}_{2.5}$ concentrations reached as low as $3.0 \pm 0.5 \mu \mathrm{g} \cdot \mathrm{m}^{-3}$. Extended periods of rainfall were found to not only "cleanse" the air, but to leave the region with a more uniform $\mathrm{PM}_{2.5}$ concentration.

This study found that the resulting spatial scales calculated from data collected each day varied, depending on the synoptic weather pattern, from $0.8 \mathrm{~km}$ to $5.2 \mathrm{~km}$ with the majority of data falling in the $1.7 \mathrm{~km}$ range. To fully understand the relationship between spatial scale and weather systems a longer study on a larger scale needs to be conducted.

The data gathering method used in this paper deployed on a larger scale can help garner a greater understanding of the neighborhood scale variability of $\mathrm{PM}_{2.5}$ concentrations. This can be accomplished by attaching the sensor package to postal or other daily driven vehicles across the country. The data could then be incorpo- 
rated into the satellite estimates to improve their accuracy and help with future models for air quality forecasting.

\section{Acknowledgements}

The authors greatly appreciate the support of NASA with research funding through award NNX11AL18G. The views expressed in this paper are those of the authors and do not necessarily represent the views of NASA.

\section{References}

[1] Brook, R.D., Rajagopalan, S., Pope, I., Arden, C., Brook, J.R., Bhatnagar, A., Diez-Roux, A.V., Holguin, F., Hong, Y., Luepker, R.V., Mittleman, M.A., Peters, A., Siscovick, D., Smith, J., Sidney, C., Whitsel, L. and Kaufman, J.D., American Heart Association Council on Epidemiology and Prevention, Council on the Kidney in Cardiovascular Disease, and Council on Nutrition, Physical Activity and Metabolism (2010) Particulate Matter Air Pollution and Cardiovascular Disease an Update to the Scientific Statement from the American Heart Association. Circulation, 121, 23312378. http://dx.doi.org/10.1161/CIR.0b013e3181dbece1

[2] Brook, R.D., Bard, R.L., Kaplan, M.J., Yalavarthi, S., Morishita, M., Dvonch, J.T., Wang, L., Yang, H.-Y., Spino, C., Mukherjee, B., Oral, E.A., Sun, Q., Brook, J.R., Harkema, J. and Rajagopalan, S. (2013) The Effect of Acute Exposure to Coarse Particulate Matter Air Pollution in a Rural Location on Circulating Endothelial Progenitor Cells: Results from a Randomized Controlled Study. Inhalation Toxicology, 25, 587-592. http://dx.doi.org/10.3109/08958378.2013.814733

[3] Brook, R.D., Xu, X., Bard, R.L., Dvonch, J.T., Morishita, M., Kaciroti, N., Sun, Q., Harkema, J. and Rajagopalan, S. (2013) Reduced Metabolic Insulin Sensitivity Following Sub-Acute Exposures to Low Levels of Ambient Fine Particulate Matter Air Pollution. Science of the Total Environment, 448, 66-71. http://dx.doi.org/10.1016/j.scitotenv.2012.07.034

[4] Pope, I., Arden, C., Brook, R.D., Burnett, R.T. and Dockery, D.W. (2011) How Is Cardiovascular Disease Mortality Risk Affected by Duration and Intensity of Fine Particulate Matter Exposure? An Integration of the Epidemiologic Evidence. Air Quality Atmosphere and Health, 4, 5-14. http://dx.doi.org/10.1007/s11869-010-0082-7

[5] Ballester, F., Medina, S., Boldo, E., Goodman, P., Neuberger, M., Iniguez, C., Kunzli, N. and Apheis, N. (2008) Reducing Ambient Levels of Fine Particulates Could Substantially Improve Health: A Mortality Impact Assessment for 26 European Cities. Journal of Epidemiology and Community Health, 62, 98-105. http://dx.doi.org/10.1136/jech.2007.059857

[6] Boldo, E., Medina, S., Le Tertre, A., Hurley, F., Muecke, H.-G., Ballester, F., Aguilera, I., Eilstein, D. and Apheis, G. (2006) Apheis: Health Impact Assessment of Long-Term Exposure to pm2.5 in 23 European Cities. European Journal of Epidemiology, 21, 449-458. http://dx.doi.org/10.1007/s10654-006-9014-0

[7] Boldo, E., Linares, C., Lumbreras, J., Borge, R., Narros, A., Garcia-Perez, J., Fernandez-Navarro, P., Perez-Gomez, B., Aragones, N., Ramis, R., Pollan, M., Moreno, T., Karanasiou, A. and Lopez-Abente, G. (2011) Health Impact Assessment of a Reduction in Ambient pm2.5 Levels in Spain. Environment International, 37, 342-348. http://dx.doi.org/10.1016/j.envint.2010.10.004

[8] Dockery, D.W., Pope, C.A., Xu, X.P., Spengler, J.D., Ware, J.H., Fay, M.E., Ferris, B.G. and Speizer, F.E. (1993) An Association between Air-Pollution and Mortality in 6 United-States Cities. New England Journal of Medicine, 329, 1753-1759. http://dx.doi.org/10.1056/NEJM199312093292401

[9] Ginoux, P. and Torres, O. (2003) Empirical Toms Index for Dust Aerosol: Applications to Model Validation and Source Characterization. Journal of Geophysical Research-Atmospheres, 108, 4534. http://dx.doi.org/10.1029/2003JD003470

[10] Prospero, J.M. (2003) Global Dust Transport over the Oceans: The Link to Climate. Geochimica et Cosmochimica Acta, 67, A384.

[11] WHO (2014) www.who.int/mediacentre/news/releases/2014/air-pollution/en/

[12] Lary, D., Faruque, F., Malakar, N. and Moore, A. (2014) Estimating the Global Abundance of Ground Level Particulate Matter (PM2. 5) since 1997. Geospatial Health, 9, 1-40.

[13] NMI (2013) www.newmountain.com

[14] Grimm (2013) www.grimm-aerosol.com/en/

[15] Kohonen, T. and Kohonen, T. (1998) The Self-Organizing Map. Neurocomputing, 21, 1-6. http://dx.doi.org/10.1016/S0925-2312(98)00030-7

[16] Myers, D.E. (1991) Interpolation and Estimation with Spatially Located Data. Chemometrics and Intelligent Laboratory Systems, 11, 209-228. http://dx.doi.org/10.1016/0169-7439(91)85001-6 
[17] Curran, P. and Atkinson, P. (1998) Geostatistics and Remote Sensing. Progress in Physical Geography, 22, 61-78. http://dx.doi.org/10.1177/030913339802200103

[18] Loughner, C.P., Lary, D.J., Sparling, L.C., Cohen, R.C., De Cola, P. and Stockwell, W.R. (2007) A Method to Determine the Spatial Resolution Required to Observe Air Quality from Space. IEEE Transactions on Geoscience and Remote Sensing, 45, 1308-1313. http://dx.doi.org/10.1109/TGRS.2007.893732

[19] Schwanghart, W. (2015) Variogramfit. http://www.mathworks.com/matlabcentral/fileexchange/25948-variogramfit

[20] EPA (2012) www.epa.gov/airquality/particlepollution/2012/decfsstandards.pdf 